\title{
Pruritus in hemodialysis patients
}

\section{Maryam Akhyani ${ }^{1}$, Mohammad-Reza Ganji ${ }^{2}$, Nasrin Samadi3 ${ }^{3}$ Behnaz Khamesan ${ }^{4}$ and Maryam Daneshpazhooh*1}

Address: ${ }^{1}$ Department of dermatology, Tehran University of Medical Sciences, Razi Hospital, Tehran, Iran, ${ }^{2}$ Department of nephrology, Tehran University of Medical Sciences, Dr. Shariati hospital, Tehran, Iran, ${ }^{3}$ Department of pathology, Tehran University of Medical Sciences, Sina hospital, Tehran, Iran and ${ }^{4}$ Department of pediatrics, Iran University of Medical Sciences, Hazrat Rasool Hospital, Tehran, Iran

Email: Maryam Akhyani - ma_akhyani@yahoo.com; Mohammad-Reza Ganji - mreza@ganji.ir; Nasrin Samadi - nasrinmd@parsonline.net; Behnaz Khamesan - behnazkhamesan@yahoo.com; Maryam Daneshpazhooh* - maryamdanesh@yahoo.com

* Corresponding author

Published: 24 June 2005

BMC Dermatology 2005, 5:7 doi:10.1 186/I47I-5945-5-7
Received: 31 October 2004

Accepted: 24 June 2005

This article is available from: http://www.biomedcentral.com/I47I-5945/5/7

(C) 2005 Akhyani et al; licensee BioMed Central Ltd.

This is an Open Access article distributed under the terms of the Creative Commons Attribution License (http://creativecommons.org/licenses/by/2.0), which permits unrestricted use, distribution, and reproduction in any medium, provided the original work is properly cited.

\begin{abstract}
Background: Pruritus is one of the most bothersome symptoms in patients on maintenance hemodialysis (HD), however little progress is seen in our understanding of its pathogenesis. The aim of this study was to evaluate the frequency of pruritus in HD patients in Tehran, Iran, and to correlate its presence and intensity with relevant clinical and laboratory parameters.

Methods: One hundred sixty-seven patients on maintenance HD at three out-patient HD units were enrolled in the study. Itch intensity was scored as mild, moderate and severe. Some relevant clinical and laboratory parameters (age, sex, xerosis, presence of neuropathy, duration of dialysis, history of atopy and laboratory findings including hematocrit, creatinine, urea, calcium, phosphorus, parathyroid hormone $[\mathrm{PTH}]$ and alkaline phosphatase) were evaluated.

Results: Pruritus was found in $41.9 \%$ of patients. The intensity of itching was mild, moderate and severe, in $51.4 \%, 11.4 \%$ and $37.7 \%$ of patients, respectively. In 22 patients $(31.4 \%)$ pruritus intensified during and after dialysis. There was no significant difference in the serum levels of creatinine, blood urea nitrogen, calcium, phosphorus, alkaline phosphatase, PTH and hematocrit between patients with and without pruritus. Age, sex, xerosis, underlying renal disease, history of atopy and duration of haemodialysis were not significantly different between the two groups. However, neuropathy was significantly more common in the pruritic group (63.8\% versus $42.1 \%)$ (pv = 0.006).

Conclusion: Clinical neuropathy was the only significant finding in the pruritic group in our study. This finding justifies further research on nerve function and neurotransmitters in hemodialysis patients and the introduction of new drugs targeting neuropathy.
\end{abstract}

\section{Background}

Pruritus often constitutes a major problem for patients with end-stage renal disease (ESRD). Unfortunately, dialysis has only a slight impact on pruritus. Therefore it is quite frustrating that an ever-increasing number of ESRD patients on HD, are waiting for transplantation, while they suffer from this tormenting symptom. According to most sources, more than half of patients undergoing HD complain of varying degrees of pruritus. [1-4] The mechanism underlying pruritus is poorly understood; current 
Table I: Comparison of clinical and laboratory parameters in HD patients

\begin{tabular}{|c|c|c|c|}
\hline Clinical \& laboratory parameters & Pruritic (mean $\pm S D$ ) & Non pruritic (mean \pm SD) & $\mathrm{P}$-value \\
\hline Age (years) & $51.54 \pm 16.63$ & $45.37 \pm 16.41$ & 0.1212 \\
\hline Time on treatment (months) & $44.42 \pm 44$ & $41.4 I \pm 44.73$ & 0.666 \\
\hline Dialysis per week & $2.6 \pm 0.55$ & $2.57 \pm 0.59$ & 0.682 \\
\hline Hematocrit $(\%)(M=39-52)(F=36-46)$ & $25.43 \pm 6.99$ & $24.95 \pm 5.43$ & 0.647 \\
\hline Serum calcium $(\mathrm{mg} / \mathrm{dl})(8.6-10.3)$ & $8.705 \pm 1.79$ & $8.707 \pm 1.44$ & 0.994 \\
\hline Serum phosphorus $(\mathrm{mg} / \mathrm{dl})(2.7-4.5)$ & $5.45 \pm 1.72$ & $5.74 \pm 1.66$ & 0.314 \\
\hline Serum alkaline phosphatase $(\mathrm{u} / \mathrm{l})(\mathrm{I} 50-450 \mathrm{u} / \mathrm{l})$ & $322.01 \pm 272.61$ & $494.56 \pm 750.76$ & 0.080 \\
\hline BUN (mg/dl) (8-20) & $|3| .3| \pm 66.0|$ & $|36.08 \pm 68.6|$ & 0.673 \\
\hline Serum creatinine $(\mathrm{mg} / \mathrm{dl})(0.4-1.3)$ & $9.43 \pm 3.21$ & $9.27 \pm 3.29$ & 0.777 \\
\hline Parathyroid hormone (pmole/l)(0.8-2.5) & $0.9 \pm 1.16$ & $1.43 \pm 0.85$ & 0.252 \\
\hline
\end{tabular}

theories include secondary hyperparathyroidism, divalent-ion abnormalities, histamine, allergic sensitization, proliferation of skin mast cells, iron deficiency anemia, hypervitaminosis $\mathrm{A}$, xerosis, neuropathy and neurologic changes, opioid system involvement (understimulation of $\kappa$ receptors or overexpression of $\mu$ receptors), cytokines, serum bile acids, nitric oxide, or some combination of these.[1,4-12] The quality of uremic pruritus varies between patients. In some it is persistent, extensive and intractable but in others it may be transitory and localized. [1] Pruritus usually begins about six months after the start of dialysis, [13] and some authors have shown a significant positive relationship with the duration of HD. [10] The aim of this study was to evaluate the frequency of pruritus in hemodialysis patients in Tehran, Iran, and its relationship with age, sex, xerosis, neuropathy, duration of dialysis, history of atopy and laboratory findings including hematocrit, creatinine, urea, calcium, phosphorus, alkaline phosphatase and PTH.

\section{Methods}

All patients ( $\mathrm{n}=167)$ on maintenance HD attending three HD units at Emam Khomeini, Dr Shariati and Sina Medical Complexes in Tehran, Iran, from 1998-1999 were enrolled in a cross-sectional study. Eighty-three were men and 84 were women. Their mean age was $47.95+/-16.73$ years with a range of $10-76$ years. The routine of dialysis was 3 times per week (except holidays) for 4 hours. The mean of dialysis sessions per week are presented in table 1. Polysulfone membranes were used as dialyser, the dialysate was mainly acetate, and sodium hypochlorite was used for sterilization. Twenty nine of the patients were diabetic, while four patients suffered from systemic lupus erythematosus (SLE), two from lymphoma and one from multiple myeloma. The etiology in the remaining cases was unknown. None of the patients presented with primary skin disease.
The patients were questioned, by a physician, if they had pruritus during the previous two weeks, and the symptoms were classified according to intensity (mild, moderate, and severe), location (generalized, head and neck, trunk and limbs), type of pruritus (episodic, persistence) and duration of HD. The patients' symptoms were recorded before a mid-week HD session and a blood sample was collected. The following laboratory tests were performed: Serum calcium, phosphorus, alkaline phosphatase, PTH, BUN, creatinine and hematocrit.

\section{Measurement of pruritus}

The severity of pruritus was assessed subjectively and scored as follows:

Mild: Episodic and localized pruritus without disturbance in usual work and sleep.

Moderate: Generalized and continuous pruritus without sleep disturbance.

Severe: Generalized and continuous pruritus with sleep disturbance.

The major emphasis was on the disturbance in usual work and sleep.

\section{Grading of xerosis}

Xerosis was graded as follows:

0 : Absent; 1 : Mild (only on legs); 2: Moderate (all of the extremities); and 3: Severe (generalized).

\section{Neuropathy}

The diagnosis of clinical neuropathy was based on the presence of paresthesia, restless leg syndrome, decreased sensations of vibration, position, light touch, pain, decreased deep tendon reflexes or muscular force. 


\section{Definition of atopy}

Positive history of asthma, atopic dermatitis (based on Hanifin-Rajka criteria [14]) or allergic rhinitis was defined as atopy.

\section{Statistical analysis}

Pruritus and non-pruritus groups were compared according to the variables. Data entry and coding was done through a database system developed with PE2 and analyzed by SPSS version 9. Student t-test and $\mathrm{X}^{2}$ score were used for statistical analysis. Statistical significance was defined as $\mathrm{p}<0.05$.

\section{Results}

Seventy patients (41.9\%) (30 women and 40 men) complained of pruritus classified as mild, moderate and severe in $51.4 \%(n=36), 11.4 \%(n=8)$ and $37.1 \%(n=26)$ of patients, respectively. The difference between the frequency of pruritus by gender was not significant ( $\mathrm{pv}>$ $0.05)$. Pruritus was episodic in $60 \%(n=42)$ and persistent in $40 \%(n=28)$ of patients. Six patients had episodic but generalized pruritus with disturbance in work or sleep and their itch was categorized as moderate or severe. In $31.4 \%(\mathrm{n}=22)$ of patients pruritus intensified during and after dialysis.

Pruritus was generalized in $70 \%(n=49)$ of patients, limited to the trunk in $14.3 \%(n=10)$, limbs $14.3 \%(n=10)$, and head and neck $1.4 \%(n=1)$. There was history of atopy in $17(24.3 \%)$ of pruritic and 20 (20.6\%) of nonpruritic patients. The difference was not significant ( $\mathrm{pv}>$ 0.05). Nine out of 21 diabetic patients, one out of 4 SLE patients and one lymphomatous patient complained of pruritus. There was no statistically significant difference between pruritus in diabetic and non-diabetic subjects ( $\mathrm{pv}$ $>0.05)$. Forty seven out of 97 non-pruritic patients had a past history of pruritus during HD treatment. Comparison of clinical and laboratory parameters in HD patients with and without pruritus is shown in table 1 . There was no significant difference among the two groups using t-test (pv $>0.05)$.

There wasn't any relationship between pruritus and xerosis in HD patients 2. Pruritus was alleviated in one patient after parathyroidectomy.

Eighty-four patients (51.3\%) suffered from peripheral neuropathy (Three patients with diabetic foot amputation were excluded). Fifty-eight had only subjective symptoms; decreased sensation of vibration, decreased deep tendon reflexes, decreased pain perception, decreased sensation of light touch, and decreased sensation of position were noted in $19,11,7,5$, and 4 cases, respectively. In the pruritic group, 44 patients $(63.8 \%)$, and in the non-pruritic
Table 2: Frequency of pruritus in HD patients according to severity of xerosis

\begin{tabular}{lll}
\hline Xerosis & Pruritic & Non pruritic \\
\hline Absent & $27(38.6 \%)$ & $33(34 \%)$ \\
Mild & $19(27.1 \%)$ & $40(41.2 \%)$ \\
Moderate & $19(27.1 \%)$ & $18(18.6 \%)$ \\
Severe & $5(07.1 \%)$ & $6(06.2 \%)$ \\
Total & $70(100 \%)$ & $97(100 \%)$ \\
\hline
\end{tabular}

$\mathrm{X}^{2} \mathrm{pv}=0.26$

group, 40 cases $(42.1 \%)$ had neuropathy. The difference was significant $(\mathrm{p}$-value $=0.006)$.

\section{Discussion}

Pruritus is one of the most prevalent presentations of uremia and occurs in 10-85\% of HD patients. [1,15-17] Difficulty in defining this very subjective symptom, the limited number of patients in most series, and the retrospective nature of some of the information, may be some of the reasons why such a wide range of figures is quoted. Recently, Urbonas et al noticed a decreasing trend in the prevalence of pruritus in HD patients and attributed it to more precise calculation of HD doses based on Kt/v or creatinine clearance measurements, introduction of new dialysers with larger surfaces as well as replacement of cuprophane fibers to more biocompatible ones made from polysulfone and amyl nitrite. $[1,10,18]$

Despite the long history of HD in Iran, to the best of our knowledge no study is published in the literature regarding the itch in Iranian HD patients. In our study, including 167 patients, pruritus was found in $41.9 \%$ of patients, severe in $37.1 \%$, moderate in $11.4 \%$, and mild in $51.4 \%$ of pruritic patients. Stahle-Backdahl et al, described pruritus in $60-65 \%$ of their cases which was severe in $8 \%$, moderate in $24 \%$, and mild in $34 \%$ of the examined patients. [19] Zucker and his colleagues reported pruritus in $48 \%$ of their HD patients at the time of the study in Tel-Aviv. [20] The figure reported from Poland by Szepietowski et al was 40.8\% [10,21]. In Kato's series from Japan, 74\% complained of pruritus [11]. Benchikhi et al reported a figure of $74.4 \%$ in HD patients from Moroc [22]. It is worth mentioning that a major drawback for studying and comparing results from different studies is the lack of a uniform way for assessment of this very subjective symptom. Recently, Yosipovitch et al has developed a comprehensive questionnaire for the assessment of pruritus and tested it in uremic patients and found it valid and reliable [23]. This questionnaire can provide data on many aspects of itching: the effect of daily life habits, physical activities and antipruritics on itch, the effect of itch on quality of life, temporal factors, location, 
severity, characteristics and exacerbating and relieving factors are all included. They found a significant correlation between the visual analogue scale and affective scores.

Uremic pruritus may be constant in $50 \%$ of cases with exacerbation or intermittent with spontaneous remissions. [24] In the majority of those affected, the itch is paroxysmal and may be localized (56\%) or generalized (44\%).[25] Seventy percent of our patients suffered from generalized pruritus as Moroccan patients.[22] Exacerbations of continuous itch are usually observed during HD or soon after, [1] which can be attributed to allergy to dialysate or dialysis membranes. [18] Exacerbation of pruritus during dialysis sessions was seen in $31.4 \%$ of HD patients in our study. In Yosipovitch series, too, itch appeared or aggravated in only $26 \%$ of patients during dialysis and the majority did not note an effect of dialysis on their itch. [23]

In Stahle-Backdahl et al's study, patients with pruritus tended to have been on dialysis treatment longer than those without pruritus. [2] Szepietowski et al showed a significant relationship between the total score of pruritus and duration of hemodialysis.[10] On the contrary, Altmeyer et al [26] described a significant improvement of itching in patients who had been on HD for long period of time: of the 23 patients with short term dialysis (2-3 years), $78 \%$ complained of pruritus, while it was seen in only $43 \%$ of 28 patients with long-term dialysis (>8 years). Murphy et al [27], however, could not confirm that pruritus decreases with progressive duration of dialysis treatment. In our study, we did not find any relationship between pruritus and duration of dialysis as seen in some previous studies. [7,19,26,27]

Xerosis is seen in the majority of patients on HD $[1,4,7,8]$ and it may contribute to pruritus. $[1,7,10,11,20]$ A relationship between the degree of xerosis and pruritus has been demonstrated in several studies, $[1,10,20,28,29]$ although others failed to find an association between skin hydration and pruritus using a skin surface hygrometer. $[11,30,31]$ Xerosis found in HD patients has been attributed to increased level of vitamin A in epidermis, atrophy of sebaceous and sweat glands and dysautonomia. $[1,7,15]$ In our study the prevalence of xerosis in pruritic and non-pruritic patients was $61.4 \%$ and $66 \%$, respectively, and we couldn't find any association between xerosis and pruritus.

Increased serum levels of magnesium, phosphorus and calcium have been proposed to be involved in uremic pruritus by some authors. $[1,9,15,24]$ It has been suggested that an increased skin divalent ions concentration may lead to microprecipitation of calcium or magnesium phosphate, which may be the cause of pruritus. [1] On the other hand, the role of magnesium itself in the modulation of nerve conduction and release of histamine from mast cells was put forward. [1] While marked improvement of uremic pruritus with low dialysate calcium and magnesium has been reported [32,33], only a few studies showed a significant correlation between serum or skin divalent ion content and the presence of pruritus. $[1,6]$ Recently, Momose et al, found increased calcium ion concentration in the deepest layers of the epidermis indicating a disrupted calcium ion gradient in the skin.[6] Like most studies $[3,22,31]$, we couldn't find any association between serum calcium and phosphorus and uremic pruritus.

Hyperparathyroidism has been proposed by some as a cause of uremic pruritus.[8] Cases of disappearance of pruritus after parathyroidectomy support this theory. $[1,4,8]$ This hormone can indirectly lead to metabolic alterations that subsequently cause pruritus.[1] On the other hand, a direct role for parathyroid hormone in causing uremic pruritus has been questioned because of the failure of intradermal injections of PTH analogs to cause pruritus, and because of negative immunohistochemical studies for PTH in skin biopsy specimens.[19]

Furthermore, no correlation between PTH levels and intensity of itching was found in most studies.[1,9,31] Although pruritus improved after parathyroidectomy in one of our cases, we couldn't find any relationship between serum PTH and pruritus in our study.

Iron deficiency anemia contributes to renal itch according to some authors, but we couldn't find any relationship between hematocrit level and uremic pruritus as shown in more recent studies[3,31].

Likewise, we couldn't find any association between HD pruritus and atopy. No previous research was recorded in the literature.

In our study there were also no significant difference between pruritic and non pruritic HD patients according to age, sex, underlying renal disease, serum alkaline phosphatase, BUN and creatinine similar to previous studies. $[1,3,4,11,20-22,31]$

Peripheral neuropathy affects up to $65 \%$ of patients starting dialysis. Some consider pruritus another manifestation of this neuropathy.[17] Contradictory data have been published about neurone-specific enolase fibers in the epidermis of HD patients. [2,34] Zakrzewska-Pniewska and Jedras found nervous dysfunction especially the somatic component related to pruritus in uremic patients. Pruritus was more frequent in patients with paresthesia in their study. Moreover the relationship between the sever- 
ity of pruritus and the incidence of paresthesia was significant. [35] On the other hand, reports showing the efficacy of lidocaine [36,37], capsaicin [9,38,39], and gabapentin $[40,41]$ in controlling uremic pruritus are in favor of a relationship between neuropathy and itching in HD patients. Yosipovitch et al reported paradoxical heat sensation an early sign of uremic sensory neuropathy. [42]

Neuropathy was significantly more frequent in patients with pruritus than without in our series, showing a figure of $63.8 \%$ versus $42.1 \%$ ( $\mathrm{pv}<0.05)$. These findings were not confounded by the presence of diabetics in the study group, as pruritus was not significantly different between diabetics and non-diabetics. Clinical neuropathy was significantly more frequent in HD patients with pruritus in Mesic's cases. [43] Winkelman et al, too, showed correlation between restless legs syndrome and pruritus. [44]

In conclusion, clinical neuropathy was the only significant finding in the pruritic group in our study. This finding justifies further research on nerve function and neurotransmitters in hemodialysis patients. Furthermore, therapeutic or preventive modalities targeting neuropathy may be effective in controlling the itch in hemodialysis patients.

\section{Authors' contributions}

MA conceived the study, participated in its design and coordination, and drafted the manuscript.

GMR participated in the design and conduct of the study.

SN and KB performed the data collection and the statistical analysis.

DM drafted the manuscript.

All authors read and approved the final manuscript.

\section{Competing interests}

The author(s) declare that they have no competing interests.

\section{References}

I. Urbonas A, Schwartz RA, Szepietowski JC: Uremic pruritus-an update. Am J Nephrol 200I, 2 I:343-350.

2. Stahle-Backdahl M: Uremic pruritus. Clinical and experimental studies. Acta Derm Venereol (Stockh) 1989, I 45(suppl): I-38.

3. Virga G, Visentin I, La Milia V, Bonadonna A: Inflammation and pruritus in hemodialysis patients. Nephrol Dial Transplant 2002, 1 7:2164-2169.

4. Greaves MW: Pruritus. In Textbook of dermatology 6th edition. Edited by: Champion RH, Burton JL, Burns DA, Breathnach SM. London: Blackwell science Ltd; 1998:623.

5. Mettang T, Pauli-Magnus C, Alscher DM: Uraemic pruritus - new perspectives and insights from recent trials. Nephrol Dial Transplant 2002, I 7: I558-63.

6. Momose A. Kudo S, Sato M, Saito H, Nagai K, Katabira Y, Funyu T: Calcium ions are abnormally distributed in the skin of hemo- dialysis patients with uraemic pruritus. Nephrol Dial Transplant 2004, 19:2061.

7. Greaves MW: Pathophysiology and clinical aspects of pruritus. In Fitzpatrick's Dermatology in general medicine 6th edition. Edited by: Freedberg IM, Eisen AZ, Wolff K, Austen KF, Goldsmith LA, Katz SL. USA: McGraw-Hill Companies, Inc; 2003:399-405.

8. Massry SG, Popovtzer MM, Coburn JW, Makoff DL, Maxwell MH, Kleeman CR: Intractable pruritus as a manifestation of secondary hyperparathyroidism in uremia. Disappearance of itching after subtotal parathyroidectomy. N Eng J Med 1968, 279:697.

9. Cho YL, Liu HN, Huang TP, Tarng DC: Uremic pruritus: Roles of parathyroid hormone and substance P. J Am Acad Dermatol 1997, 36:538-541.

10. Szepietowski JC, Sikora M, Kusztal M, Salomon J, Magott M, Szepitowski T: Uremic pruritus: a clinical study of maintenance hemodialysis patients. J Dermatol 2002, 29:621-6.

II. Kato A, Hamada M, Maruyama T, Maruyam A, Hishida A: Pruritus and hydration state of stratum corneum in hemodialysis patients. Am J Nephrol 2000, 20:437-42.

12. Yozipovitch G: Itching in the new millennium: Highlights of the Second International Workshop for the Study of Itch, Toyoma, Japan. J Am Acad Dermatol 2004, 5 I :625-7.

13. Robertson KE, Mueller BA: Uremic pruritus. Am J Health Syst Pharm 1996, I 5:2523.

14. Hanifin JM, Rajka G: Diagnostic features of atopic dermatitis. Acta Derm Venereol 1980, 92(suppl):44-47.

15. Ashmore SD, Jones CH, Newstead CG, Daly MJ, Chrystyn H: Ondansetron therapy for uremic pruritus in hemodialysis patients. Am J kidney Dis 2000, 5:827-3I.

16. Stahl-Backdahl M: Pruritus in hemodialysis patients. Skin pharmacol 1992, I:14-20.

17. Carmichael AJ, Renal itch : In Itch: Mechanisms and management of pruritus Edited by: Bernhard JD. Mc Graw-Hill, Inc; 1992:217-228.

18. Mettang T, Pauli-Magnus C: The pathophysiological puzzle of uremic pruritus-Insights and speculation from therapeutic and epidemiological studies. Perit Dial Int 2000, 20:493-494.

19. Stahle-Backdahl M, Hagermark O, Lines LE: Pruritus in patients on maintenance hemodialysis. Acta Med Scan 1988, 224:55-60.

20. Zucker I, Yosipovitch G, David M, Gafter U, Boner G: Prevalence and characterization of uremic pruritus in patients undergoing hemodialysis: uremic pruritus is still a major problem for patients with end-stage renal disease. J Am Acad Dermatol 2003, 49:842-6.

21. Szepietowski JC, Salomon J: Uremic pruritus: still an important clinical problem. J Am Acad Dermatol 2004, 5 I:842-3.

22. Benchikhi H, Moussaid L, Doukaly O, Ramdani B, Zaid D, Lakhdar H: Hemodialysis-related pruritus. A study of 134 Moroccans. Nephrologie 2003, 24:|27-3|.

23. Yosipovitch G, Zucker I, Boner G, Gafter U, Shapira Y, David M: A questionnaire for the assessment of pruritus: validation in uremic patients. Acta Dermatol Venereol 200 I, 81: 108-III.

24. Szepietowski J: Selected elements of the pathogenesis of pruritus in hemodialysis patients: My own study. Med Sci Monti 1996, 2:343-347.

25. Gilchrest BA, Stern RS, Steinman TI, Brown RS, Arndt KA, Anderson WW: Clinical features of pruritus among patients undergoing maintenance hemodialysis. Arch Dermatol 1982, I 18:154-156.

26. Altmeyer P, Kachel HG, Junger M, Koch KM, Holzmann H: Skin changes in long-term dialysis patients. Clinical study. Hautarzt 1982, 33:303-309.

27. Murphy M, Carmichael AJ: Renal itch. Clin Exp Dermatol 2000, 25:103-106.

28. Morton CA, Lafferty M, Hau C, Henderson I, Jones M, Lowe JG: Pruritus and skin hydration during dialysis. Nephrol Dial Transplant 1996, I I:203|-2036.

29. Giocoechea M, de Sequera P, Ochando A, Andrea C, Caramelo C: Uremic pruritus: An unresolved problem in hemodialysis patients. Nephron 1999, 82:73-74.

30. Yosipovitch G, Tur E, Morduchowicz G, Boner G: Skin surface pH, moisture and pruritus in haemodialysis patients. Nephrol Dial Transplant 1993, 8: I I29-I I 32.

31. Ostlere LS, Tylor C, Baillod R, Wright S: Relationship between pruritus, transepidermal water loss, and biochemical mark- 
ers of renal itch in hemodialysis patients. Nephrol Dial Transplant 1994, 9:1302-I304.

32. Carmichael AJ, Dickinson F, McHugh MI, Martin AM, Farrow M: Magnesium-free dialysis for uremic pruritus. $B r$ Med J I988, 297:584-85.

33. Kyriasis J, Glotsos J: Dialysate calcium concentration of $=$ or $<$ I.25 mmol/l: Is it effective in suppressing uremic pruritus? Nephron 2000, 84:85-86.

34. Fantini F, Baraldi A, Sevignani C, Spattini A, Pincelli C, Giannetti A: Cutaneous innervation in chronic renal failure patients. An immunohistochemical study. Acta Dermatol Venereol (Stockh) 1992, 72:102-5.

35. Zakrzewska-Pniewska $B$, Jedras $B$ : Is pruritus in chronic uremic patients related to peripheral somatic and autonomic neuropathy? Study by $R-R$ interval variation test (RRIV) and by sympathetic skin response (SSR). Neurophysiol Clin 200I, 31:|8|-93.

36. Tapia L, Cheigh JS, David DS: Pruritus in dialysis patients treated with parenteral lidocaine. N Eng J Med 1988, I 7:180-89.

37. Tapia L, Cheigh JS, David DS, Sullivan JF, Saal S, Reidenberg MM, Stenzel $\mathrm{KH}$, Rubin AL: Pruritus in dialysis patients treated with parenteral lidocaine. N Engl J Med I977, 296:26I-2.

38. Weisshaar E, Dunker N, Gollnick H: Topical capsaicin therapy in humans with hemodialysis-related pruritus. Neurosci Lett 2003, 345: $192-4$.

39. Tarng DC, Cho YL, Liu HN, Huang TP: Hemodialysis-related pruritus: a double-blind, placebo-controlled, crossover study of capsaicin $\mathbf{0 . 0 2 5} \%$ cream. Nephorn 1996, 72:617-22.

40. Gunal AI, Ozalp G, Yaldas TK, Gunal SY, Kirciman E, Celiker H: Gabapentin therapy for pruritus in hemodialysis patients: a randomized, placebo-controlled, double-blind trial. Nephrol Dial Transplant 2004, 19:3137-9.

4I. Manenti L, Vaglio A, Costantino E, Danisi D, Oliva B, Pini S, Prati E, Testori A: Gabapentin in the treatment of uremic itch: an index case and a pilot evaluation. J Nephrol 2005, I 8:86-9I.

42. Yosipovitch G, Yarnitsky D, Mermelstein V, Sprecher F, Reiss J, Witenberg C, Hemli JA, Boner G: Paradoxical heat sensation in uremic polyneuropathy. Muscle Nerve 1995, I 8:768-7I.

43. Mesic E, Tabakovic M, Habul V, Atic M, Lekic S, Resic H, Halilbasic A, Trnacevic S, Halilbasic A: Clinical characteristics of uremic pruritus in hemodialysis patients. Acta Med Croatica 2004, 58:377-80. (abstract)

44. Winkelman JW, Chertow GM, Lazarus JM: Restless legs syndrome in end-stage renal disease. Am J Kidney Dis 1996, 28:372-8.

\section{Pre-publication history}

The pre-publication history for this paper can be accessed here:

http://www.biomedcentral.com/1471-5945/5/7/prepub

\section{Publish with Bio Med Central and every scientist can read your work free of charge}

"BioMed Central will be the most significant development for disseminating the results of biomedical research in our lifetime. "

Sir Paul Nurse, Cancer Research UK

Your research papers will be:

- available free of charge to the entire biomedical community

- peer reviewed and published immediately upon acceptance

- cited in PubMed and archived on PubMed Central

- yours - you keep the copyright
BioMedcentral 